\title{
Barriers and Factors Affecting Personal Protective Equipment Usage in St. Mary's Hospital Lacor in Northern Uganda
}

\author{
T.R Okello ${ }^{1}$, Kansime ${ }^{2}$, J Odora ${ }^{3}$, J A Apio ${ }^{4}$, I Pecorella ${ }^{5}$ \\ ${ }^{1}$ Senior Consultant Surgeon, Head of surgery Department St Mary's Hospital \\ Lacor, Senior Honorary lecturer Faculty of Medicine Gulu, Chairman Infection \\ Control Commitee, \\ ${ }^{2}$ Consultant Physician, Head of Department Medicine, St Mary's Hospital Lacor, \\ Vice Chairman Infection Control Committee. \\ ${ }^{3}$ Head of department of Pharmacy St Mary's Hospital Lacor, Secretary \\ Chairman Infection Control Committee. \\ ${ }^{4}$ Vice Secretary Chairman Infection Control Committee. \\ ${ }^{5}$ Professor of Histo-pathology, Sapienza University of Rome - Italy, Dept of \\ Radioplogical, Oncological and Anatomic Pathology Sciences, Rome, Lazio, \\ Italy
}

Correspondence to: Tom R Okello, Email:<okellotomrich@yahoo.co.uk> https://dx.doi.org/10.4314/ecajs.v22i1.8

Background: To protect health workers (HCWs) from risky occupation exposure, CDC developed the universal precautions (Ups) including Personal Protective Equipment (PPEs). However compliance to it by HCWs has remained poor even in high-risk clinical situation. The objective of this study was to identify and describe the factors that influence a HCW' decision to wear PPEs and the barriers that exist in preventing their use

Methods: A cross-sectional survey was carried out in the St. Mary's Hospital Lacor in all the wards to collected quantitative information as well as qualitative and observational data on PPE use

Results: Out of the total 59 respondents, $2 \%$ do not know the purpose of PPE, $23.7 \%$ do not know how to don and doff PPEs, $13.6 \%$ do not use PPE even when indicated and $10 \%$ are not using an appropriate PPE. The main barriers relates to poor fitting and weak domestic gloves, few of aprons, frequent stock out and inadequate PPE as well as lack of training in PPE

Conclusion: This study provides a baseline for measuring the effectiveness of interventions to improve compliance.

\section{Introduction}

Worldwide, three million Health Care Workers (HCWs) experience per-cutaneous exposure to blood-borne viruses such as hepatitis $B$, hepatitis $C$ and HIV per year ${ }^{1}$.To mitigate this danger CDC developed the universal precautions (Ups) in 1987 and later updated it in $1996^{2}$. Compliance with UPs protects health worker as well as reduces their risk of infections ${ }^{3,4}$. Related to Universal precaution practices, proper donning and doffing of Personal Protective 


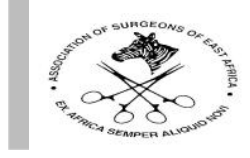

Equipment (PPE) has been identified as key in reducing muco-cutaneous injuries and contact with Blood Body fluid splash. The use of PPE is essential in Infection Control (IC) and protects HCWs from acquiring dangerous infection and diseases of epidemic proportion. However, compliance with universal precautions amongst HCWs is poor even in the face of high-risk clinical situattion ${ }^{6}$.

Lack of comfort/fit, and fogging of eyewear and the need to scratch as well as young age and lack of safety training has been reported as the main impedance to use of PPE ${ }^{7}$. Furthermore, amongst HCWs a large proportion (76\%) feel the barrier to PPE use relates to inadequate training in the use of PPE ${ }^{8}$. Being too busy to wear PPE and, not using PPE because colleagues also do not use or feeling that PPE may offend patients, and discomfort in PPE use was reported to be a significant barrier to PPE use amongst the nurses compared to doctors $(P<0.004)$ by Kotwal and Taneja ${ }^{8}$.

In Uganda, very few studies, with varying focus and differing research setting, have been conducted in this field. Thus, the present study was conducted to assess the knowledge, practices and barriers to compliance to PPE among HCWs in St. Mary's Hospital Lacor to help target any appropriate intervention programs. St. Mary's Hospital Lacor is a large private not for profit health facility located in Northern Uganda, has 482 beds and is a teaching hospital for Gulu University faculty of Medicine. The main objective of this study was to identify and describe the factors that influence a HCWs' decision to wear Personal Protective Equipment (PPE) and the barriers that exist in preventing their use.

\section{Subjects and Methods}

A cross-sectional survey was carried out in the St. Mary's Hospital Lacor in March 2017 all the wards were included. The survey was done during the morning duty shift, the respondents consisted of, Nurses, nursing aids, cleaners and doctors on morning duty. Morning duty is often characterized by ward hygiene, cleaning, Bed making, collection of samples, ward round, wound dressing, drug administration and injection. Those working in the outpatient unit, labour room, and Operation Theater were excluded because they form a different PPE user category.

Data was collected qualitatively and quantitatively. Qualitative data collection comprised of observation as well as interview of ward staff by a trained research assistant while quantitative data was collected by filling a self-administered World Health Organisation(WHO) PPE standardized questionnaire by respondents. Data was collected by trained research assistants who were also available for consultation. Respondents offered verbal consent prior to administration of the questionnaire. Data was entered and analysed using SPSS version 15. Chi square test was used for comparing proportions and statistical significance was taken as $\mathbf{P}$ value $\leq \mathbf{0 . 0 5}$.

\section{Results}

Approximately 65 respondents fill a self-administered questionnaire, but 6 were invalid hence only 59 cases were analyzed. Table 1 show that all categories of health workers 


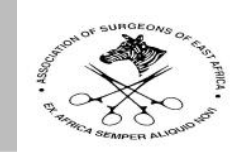

participated in the study. However, the biggest proportion was formed by enrolled nurses $22 \%$, followed by Registered nurses (15.3\%) nursing aids $(13.6 \%)$, cleaners $(8.5 \%)$ and doctors $(5.1 \%)$. There was a group who preferred not to state their employment carder and this were particularly from Obstertric ward. Perhaps they feared being personally identified during analysis.

\section{Distribution of the Wards}

From Table 2, all the wards in St. Mary's Hospital Lacor participated in the study. Obsteric ward represented the biggest proportion (17\%) followed by the Children ward and the septic surgical ward - surgery 1 (11.9\%) where all surgical patients with septic lesion like necrotizing fasciitis, osteomyelitis, abscesses, urosepsis etc are admitted. Casualty, burns unit and Gyn ward accounted for $10.2 \%$ each while surgery 2 (the clean surgical unit), Isolation unit, and Medicine ward accounted for $8.5 \%$ each.

\section{Factors and Barrier affecting PPE Usage}

According to Table 3, approximately $30.5 \%$ of the hospital employees have had NO training on PPE use. Most of the respondents stated that they only learnt about PPE on their job, this lack of training could affect compliance to PPE use. Furthermore, $23.7 \%$ of the HCWs in our hospital do not know how to don and doff PPEs. Only $86.4 \%$ of staffs don PPE when carrying a procedure that necessitates use of PPE and $13.6 \%$ do not use PPE even when indicated.

Even when all the respondents know and agree that PPEs are important in their day to day job, availability and access to PPE is still a problem, with $57.6 \%$ of respondents stating that PPEs are inadequate in the ward where they work. On any one day, $10 \%$ of the HCWs in the hospital are not using an appropriate PPE and 56\% aver that there are problem that affect use of PPE and indeed $2 \%$ of staffs do not know the purpose of PPE in their Jobs. Approximately $10 \%$ of the respondent reported that use of PPEs is not promoted and enforced in their respective wards, a function incumbent on the ward in-charge.

However by comparison, Doctors and RNs were more likely to use PPEs compared to Enrolled nurses and cleaners (P-value 0.009) andsome Wards (Burns unit, Surgery 1, Children ward, and Medicine) were more likely to have adequate PPEs available for the day to day ward work than Surgery 2, Obstetrics, Gynecology,, TBW, ISO) P-value 0.001. It appears therefore that some ward in-charges do not enforce availability, access and use of PPEs.

\section{Problems affecting PPE Use}

Qualitative analysis revealed that there was a problem with the domestic gloves, either were too large and fell off from the hand or were weak and easily tore. It was cumbersome to use such gloves for cleanliness. Nurses were observed to be wearing examinations gloves during ward cleaning.

They said"The Black domestic gloves are too large and easily falls off from our hands, the yellow one is weak \& perforates easily" 
Table 1. Carder of Employees

\begin{tabular}{|l|c|c|}
\hline Qualification & Frequency & Percent (\%) \\
\hline Cleaner & 5 & 8.5 \\
\hline Nurse aid & 8 & 13.6 \\
\hline Enrolled nurse & 13 & 22 \\
\hline Registered nurse & 9 & 15.3 \\
\hline Doctors & 3 & 5.1 \\
\hline Not stated & 19 & 32.2 \\
\hline Mid wife & 2 & 3.4 \\
\hline Total & $\mathbf{5 9}$ & $\mathbf{1 0 0}$ \\
\hline
\end{tabular}

Table 2. Distribution of the Wards

\begin{tabular}{|l|c|c|}
\hline Ward & Frequency & \multicolumn{2}{|c|}{ Percent (\%) } \\
\hline Surgery 1(Septic) & 7 & 11.9 \\
\hline Surgery 2 (Clean) & 5 & 8.5 \\
\hline Obstetric ward & 10 & 16.9 \\
\hline Gyn ward & 6 & 10.2 \\
\hline Children Ward & 7 & 11.9 \\
\hline Medicine & 5 & 8.5 \\
\hline Isolation & 5 & 8.5 \\
\hline TB ward & 2 & 3.4 \\
\hline casualty & 6 & 10.2 \\
\hline Burns unit & 6 & 10.2 \\
\hline Total & $\mathbf{5 9}$ & 100 \\
\hline
\end{tabular}

Table 3. Appraisal of PPE Usage Aspects

\begin{tabular}{|l|l|l|}
\hline PPE Appraisal Item & $\begin{array}{l}\text { Affirmative } \\
\text { (Frequency) }\end{array}$ & $\begin{array}{l}\text { NO } \\
\text { (Frequency) }\end{array}$ \\
\hline Do you know purpose of PPE in Job & $58(98 \%)$ & $1(2 \%)$ \\
\hline Have you had any training in PPE use & $41(69.5 \%)$ & $18(30.5 \%)$ \\
\hline Do you know how to wear and remove a PPE & $45(76.3 \%)$ & $14(23.7 \%)$ \\
\hline Is the Use of PPE promoted on your ward & $53(90 \%)$ & $6(10 \%)$ \\
\hline Do you use PPE all the time when indicated & $51(86.4 \%)$ & $8(13.6 \%)$ \\
\hline Is the PPE in use adequate for you day to day work & $25(42.4 \%)$ & $34(57.6 \%)$ \\
\hline Have you used PPE in the last 24hours & $53(90 \%)$ & $6(10 \%)$ \\
\hline Do have you problems in using PPE & $33(56 \%)$ & $26(44 \%)$ \\
\hline $\begin{array}{l}\text { Do you think PPE is important in your day to day } \\
\text { work }\end{array}$ & $59(100 \%)$ & $0(0 \%)$ \\
\hline Total & $\mathbf{5 9}$ & $\mathbf{1 0 0 \%}$ \\
\hline
\end{tabular}




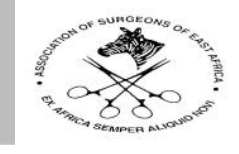

Aprons were few on the wards, and in some wards they were only selectively used and reserved for procedures and some carders. Some wards lacked even a single apron. There was lack of storage room for PPEs, they kept them in the toilet.

"Aprons in our ward is used during evacuation only"...said one staff of Gynae ward. "In isolation ward we have no aprons"....said staffs of Isolation ward.

\section{Problem Affecting PPE Use}

From Figure 1, the main problems affecting PPE availability, access and use included inadequate quantity, PPE being too large and easily falls of, particularly the domestic gloves that is used for cleaning. Frequent stock out of PPE as well as lack of training are amongst the problem facing PPE use. However a big proportion did not specifically state their main impediment to PPEs

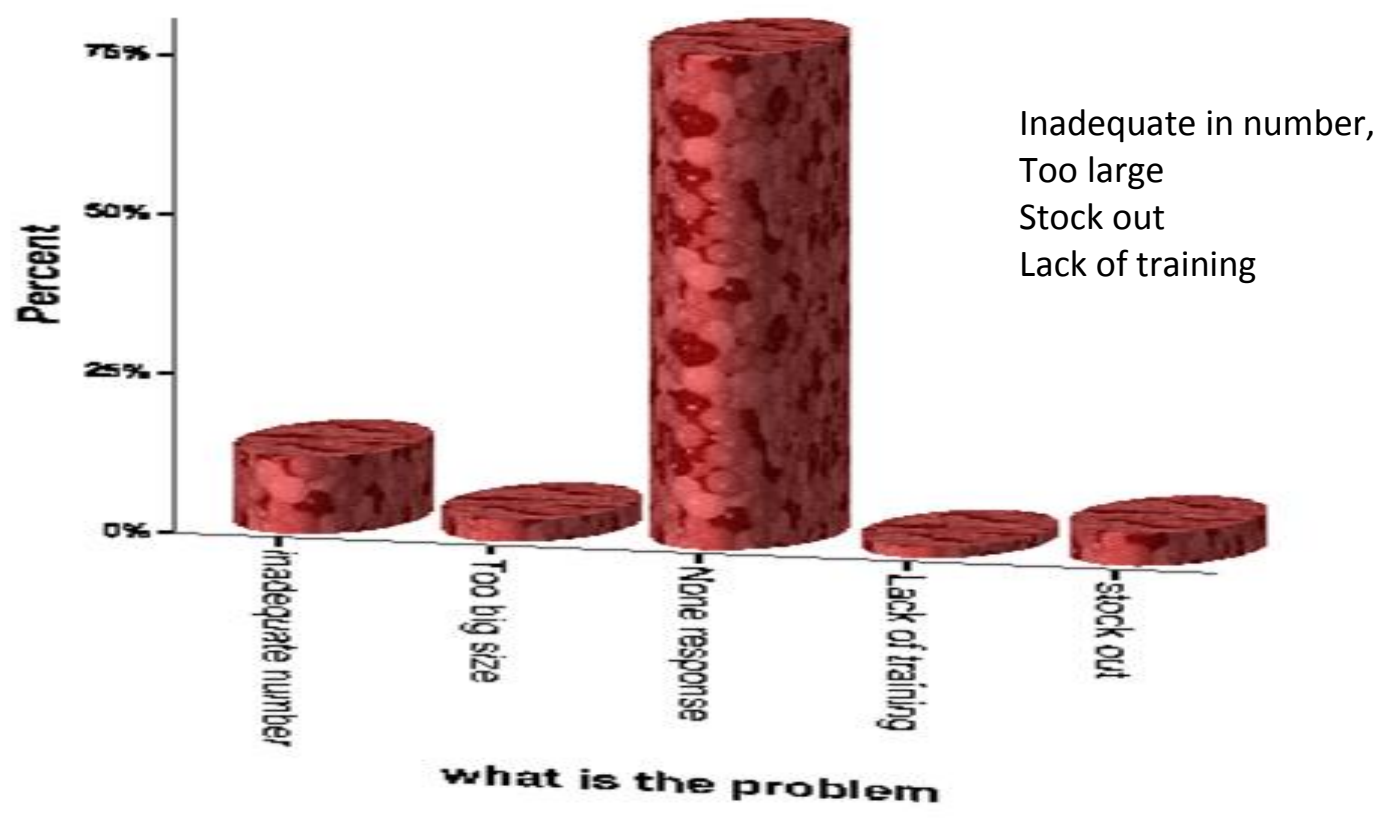

\section{Discussion}

Figure 1. Problem of PPE Usage

Proper use and compliance to PPE protocol is particularly important when carrying out invasive surgical procedures. It (PPE) provides health care workers with a barrier to prevent human contact with viruses like Ebola and potential transmission of the disease. In a metaanalysis,Verbee, ljaz, Mischke, Ruotsalainen, Mäkelä et al, (2016) found that gowns protected better than aprons, while double gloving led to less contamination compared to single gloving (Relative Risk (RR) $0.36 ; 95 \% \mathrm{Cl} 0.16$ to 0.78 ) and training at least reduced non-compliance with doffing procedures (OR $0.45 ; 95 \% \mathrm{Cl} 0.21$ to 0.98). Much as training is important in ensuring compliance to PPE use, $30.5 \%$ of our staffs report having no training in PPE. It is therefore important to address this concern as soon as possible. 


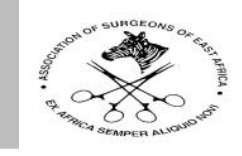

In this study, poor fitting and uncomfortable PPE was reported highly on domestic gloves used for cleaning. This type of PPE is commonly used by cleaners, nursing aid, and nurses during ward hygiene. Kotwal and Taneja $(2010)^{8}$ reported similar factor as a barrier to PPE use predominantly amongst the nurses. This study found that cleaners and enrolled nurses are less likely to use PPE compared to Registered nurses and doctors. This could be related to training and awareness of the importance of PPE. On a day by day basis, $10 \%$ of the hospital staff carry out procedures without using PPE even when indicated. Similar result was found by MacFarlane, Chapman, Benke,et al (2008) where they found, up to $10-40 \%$ of farmers routinely do not use PPE at all ${ }^{10}$. Besides discomfort, PPE introduces additional physiological burden to the user in terms increase in heat stress, heart rate and core temperature significantly ${ }^{11}$. This could affect compliance to the recommended PPEs unless there is system for cooling the room. Some barrier to PPE use however are personality and behavioral related, or example in one study setting, attending surgeons were least likely to use PPE compared to surgery residents and $84 \%$ paramedics, believe Eye protection, and wearing masks interfere with some medical procedures ${ }^{6,12 .}$

Inadequacy, poor access and unavailability of the PPE itself were report by $57.6 \%$ of the hospital staff. They reported frequent stock outs of PPE, inadequate number of PPE such that there is total lack of aprons in some wards and in some wards only certain procedures are allowed to use PPE while others are not. According to our findings $10 \%$ of the wards do not promote the use of PPE and some are more significantly like to have PPE than others.

According to Rahel, Jack, Jennifer et al (2008).lack of access to safety devices is major barrier to their use hence increased availability, training, and improvement of safety equipment are needed to better PPE compliance ${ }^{12}$.Work-to-rest ratio that avoids dehydration and reducing heat stress are addition measures that improves PPE compliance ${ }^{11}$. It is therefore important to make PPEs available, train HCWs in their use as well as make the PPE and its user ergonometry friendly in order to address PPE barrier.

\section{Conclusion}

Compliance with universal precautions is poor amongst HCWs and this study provide a baseline for measuring the effectiveness of interventions to improve compliance.

\section{Acknowledgment}

To members of the Infection control committee and ward in-charges of St Mary's Hospital Lacor.

\section{References}

1. World Health Report 2002: Reducing risks, promoting healthy life. Available from: http://www.who.int/whr/en.

2. Universal precautions for prevention of Transmission of HIV and other blood borne infections. Available on http://www.cdc.gov/ncidod/dhqp/bp_universal_precautions.html 
3. Curran E. Reducing the risk of health care acquired infection. Nurs Stand 2001;16:4552 ,

4. Sharbaugh RJ. The risk of occupational exposure and infection with infectious disease. NursClin North Am 1999;34:493-506 PUBMED

5. O'Hara LM, Yassi A, Bryce EA, van Rensburg AJ et al (2017). Infection control and tuberculosis in health care workers: an assessment of 28 hospitals in South Africa. Int J Tuberc Lung Dis. 2017 Mar 1;21(3):320-326. doi: 10.5588/ijtld.16.0591.

6. Evanoff B, Kim L, Mutha S, Jeffe D, Haase C et al (1999). Compliance With Universal Precautions Among Emergency Department Personnel Caring for Trauma Patients Annals of Emergency Medicine, Volume 33, Issue 2, 1999, Pages 160-165, http://dx.doi.org/10.1016/S0196-0644(99)70389-6

7. Lombardi D.A, Verma S.K, Brennan M.J, Perry J,(2009). Factors influencing worker use of personal protective eyewear, Accident Analysis \& Prevention, Volume 41, Issue 42009, Pages 755-762, http://dx.doi.org/10.1016/j.aap.2009.03.017

8. Kotwal A and Taneja D K. (2010) Health care workers and universal precautions: Perceptions and determinants of non-compliance. Indian J Community Med 2010; 35:526-8.

9. Verbeek JH, ljaz S, Mischke C, Ruotsalainen JH, Mäkelä E et al (2016). Personal protective equipment for preventing highly infectious diseases due to exposure to contaminated body fluids in healthcare staff. Cochrane Database Syst Rev.2016 CD011621. doi: 10.1002/14651858.CD011621.pub2

10. MacFarlane E,A, Chapman A, Benke G, Meaklim J, Sim M, and McNeil J (2008), Training and other predictors of personal protective equipment use in Australian grain farmers using pesticides. BMJ Publishing Group, Volume 65, Issue 2, 2008 http://dx.doi.org/10.1136/oem.2007.034843]

11. Coca A, Quinn T, Kim JH, et al, (2017). Physiological Evaluation of Personal Protective Ensembles Recommended for Use in West Africa. Disaster Med Public Health Prep.2017:1-7. doi: 10.1017/dmp.2017.13. [Epub]

12. Rahel M, Jack K. L.Jennifer T. L. et al (2008). Provision and use of personal protective equipment and safety devices in the National Study to Prevent Blood Exposure in Paramedics, American Journal of Infection Control, Volume 36, Issue 10, December 2008, Pages 743-749 http://dx.doi.org/10.1016/j.ajic.2008.04.250 